\title{
Aplicación y gestión de los planes de igualdad. La asignatura pendiente
}

\author{
Application and management of equality plans. \\ The pending subject
}

\author{
Alejandra Selma Penalva* \\ Profesora Titular de Universidad. Departamento \\ de Derecho del Trabajo y de la Seguridad Social. \\ Universidad de Murcia \\ ORCID: 0000-0003-2116-0057
}

Recibido: $14 / 03 / 2020$

Aceptado: 05/04/2020

doi: https://doi.org/10.20318/femeris.2020.5385

Resumen. El legislador, constantemente intenta introducir mecanismos para favorecer la plena igualdad entre mujeres y hombres en el entorno laboral. Con el RD-Ley 6/2019 se intentan combatir algunos problemas que existían y que restaban eficacia práctica a los planes de igualdad. Pese a todo, todavía quedan cuestiones pendientes de respuesta que sería oportuno clarificar en un futuro cercano con el fin de aprovechar todo el potencial intrínseco que sin duda tienen los planes de igualdad, aunque hasta ahora, sus efectos reales hayan sido mucho menores a los esperados. y control.

Palabras clave: plan de igualdad, reformas legales, propuestas de mejora, seguimiento

Abstract. The lawgiver constantly tries to introduce mechanisms to promote full equality between women and men in workplaces. The RD-Law 6/2019 tries to fight against some problems that existed and that made practical equality plans less effective. In spite of everything, there are still questions pending answer that it would be opportune to clarify in the near future in order to take advantage of all the intrinsic potential that equality plans undoubtedly have, although, until now, their real effects have been much less than expected.

Keywords: equality plan, legal reforms, improvement proposals, monitoring and control.

"aselma@um.es 


\section{El plan de igualdad como figura dinámica}

Pese a que la LO 3/2007 lleve ya prácticamente trece años de vigencia, sorprende comprobar los escasos efectos prácticos que ha dejado sentir en el entorno laboral. Pese al carácter tajante de sus postulados, no se ha logrado combatir la brecha de género en salarios y pensiones que, año tras año, confirman los datos estadísticos. Año tras año las mujeres siguen presentando mayores tasas de temporalidad y parcialidad que los varones, concentrando la práctica totalidad de las situaciones de excedencia y reducción de jornada por cuidado de hijos que se solicitan en España, y ocupando las categorías profesionales de menor cualificación y retribución ${ }^{1}$. Parece entonces que, la obligación de incluir la perspectiva de género (85.1. in fine ET), en general, y el plan de igualdad, en particular previsto para las empresas de más de 150 trabajadores (por el momento), no han sido suficientes para remediar el problema.

Precisamente por lo que respecta a los planes de igualdad como estrategias directamente destinadas a combatir la desigualdad de género en la empresa, se ha de poner de manifiesto que, muchas veces, por error o negligencia, no se hace de ellos una utilización correcta, por lo que difícilmente van a poder cumplir el objetivo que los justifica.

Uno de los errores más frecuentes consiste en creer que el proceso de elaboración de un plan de igualdad concluye en el momento en el que los negociadores acuerdan una serie de medidas de actuación. Nada más lejos de la realidad.

Es importante insistir en que todas las fases implícitamente referenciadas en el texto de la ley, son imprescindibles para la constitución de un verdadero plan de igualdad: diagnóstico, negociación ${ }^{2}$, seguimiento y evaluación. Todas ellas son igualmente importantes para garantizar que el plan de igualdad cumpla los objetivos que le dan razón de ser. Y es que en realidad el legislador ha previsto un sistema basado en el sistema de ensayoerror, en virtud del cual, a las iniciativas inicialmente previstas para lograr mejorar la igualdad de género en la empresa, necesariamente hay que sumar una serie de técnicas destinadas a garantizar el efectivo cumplimiento de las previsiones del plan, a corregir las deficiencias detectadas en materia de igualdad de géneros $y$, posteriormente, sustituirlas por otras si con el transcurso del tiempo éstas no demuestran alcanzar los resultados esperados. Si se omite o posterga cualquiera de estas fases, el plan de igualdad pasará a tener un valor meramente simbólico dentro de la estructura empresarial, sin aplicabilidad real. La propia esencia del plan de igualdad, lo hace estar destinado a ser un instrumento de mejora de la política de igualdad implantada en la empresa, y para lograrlo, resulta imprescindible configurarlo como un instrumento dinámico, abierto a constantes actualizaciones y mejoras.

\footnotetext{
${ }^{1}$ Datos que cada año, confirman las estadísticas publicadas por el INE, y cuyo alcance práctico, se valora en AAVV, “Memoria sobre la situación socioeconómica y laboral de España", Consejo Económico y Social, Madrid, 2019.

${ }^{2}$ Cuestión sobre la que insisten las SSTS (Sala de lo Social), de 9 de mayo de 2017 (no. rec. 85/2016) y de 13 de septiembre de 2018 (no․ rec. 213/2017), recordando la imposibilidad de las empresas de elaborar un plan de igualdad de forma unilateral y la nulidad del plan promulgado sin cumplir estos presupuestos (se infiere que, sin que hayan mediado maquinaciones insidiosas, intencionadamente destinadas a paralizar el proceso negociador).
} 
Así pues, técnicamente sólo podrán recibir la calificación de "planes de igualdad" aquellos textos elaborados siguiendo el procedimiento descrito y sin omitir ninguna de sus fases, que finalmente sean aprobados en el seno de un proceso de negociación con los trabajadores (de hecho, habitualmente, suelen formar parte del texto de un convenio colectivo, aunque también pueden aprobarse en el seno de un proceso negociador ad hoc).

Pese a ello, es habitual comprobar que, nuestras empresas utilizan de forma extremadamente amplia la calificación de "plan de igualdad", para hacer referencia a compromisos que, en realidad, no se ajustan en absoluto a la denominación que les ofrecen. Así pues, no cabe calificar como un verdadero "plan de igualdad" las posibles medidas o conjunto de medidas que, llegado el momento, pudiera reconocer de forma unilateral el empresario, aunque éstas persiguiesen mejorar la igualdad entre hombres y mujeres en el seno de la empresa, sin haber cumplido el trámite de consulta con los representantes de los trabajadores que exige la norma. Tampoco serán verdaderos planes de igualdad las declaraciones de intenciones, las reiteraciones de los derechos ya contemplados en la ley en materia de conciliación e igualdad de género, o las cláusulas que, por ser excesivamente genéricas, no tengan exigibilidad directa ${ }^{3}$.

\section{La olvidada comisión de igualdad y su valor esencial en el proceso de elaboración, seguimiento y revisión de los planes de igualdad}

Precisamente por lo que respecta a las fases de control y evaluación de la incidencia práctica de las medidas aportadas, resulta especialmente importante disponer del apoyo de personal de la empresa que, específicamente, tenga atribuidas estas funciones. De tal forma, aunque, a juzgar por la LO 3/2007, no forma parte del contenido mínimo del plan de igualdad, resulta aconsejable constituir una "comisión de igualdad" que será la encargada no sólo de valorar los datos estadísticos obtenidos, sino también de proponer las estrategias destinadas a solventar los problemas detectados, comprobar su correcta ejecución, y llegado el caso, plantear su eventual supresión, revisión o mejora, dependiendo de cuál haya sido la evolución de la situación en la empresa.

En la práctica se trata de un tipo de comisión que puede recibir diferentes denominaciones (comisión de igualdad, comité de igualdad, comisión de seguimiento, etc.) y que se crea con la finalidad de facilitar la elaboración de los planes de igualdad y de actuar como garante del efectivo cumplimiento de las obligaciones légales y también de los com-

\footnotetext{
${ }^{3}$ Es por todos conocido que la LO 3/2007 establece que los planes de igualdad han de ser un conjunto coordinado de medidas tendentes a alcanzar la igualdad de género en la empresa, pero no se puede olvidar que lo que la citada norma persigue es que se trate de guías de actuación efectivas, con operatividad práctica que se traduzca en la consecución real de los objetivos propuestos. Por ese motivo, el segundo párrafo del art.46.1 de la citada Ley de Igualdad concreta que "los planes de igualdad fijarán los concretos objetivos de igualdad a alcanzar, las estrategias y prácticas a alcanzar para su consecución, así como el establecimiento de sistemas eficaces se seguimiento y evaluación de los objetivos fijados". Sobre este tema, véase: AAVV (2016), "El principio de igualdad en la negociación colectiva", SÁNCHEZ TRIGUEROS (dir.), KAHALE CARRILLO y VELASCO PORTERO (coord.), Colección Informes y Estudios. Serie Relaciones Laborales, Ministerio de Trabajo y Asuntos Sociales, Madrid.
} 
promisos que se hayan podido adquirir en la empresa en materia de igualdad de oportunidades entre hombres y mujeres ${ }^{4}$.

Son muchas y variadas las funciones que estas comisiones pueden tener atribuidas. Estas funciones, a su vez, pueden clasificarse en cuatro momentos o etapas -coincidentes con las fases o etapas de las que se compone un plan de igualdad- ${ }^{5}$, como la elaboración de un diagnóstico de situación, la selección de las medidas que se propone implantar en la empresa y realizar la supervisión y control de su correcta aplicación, centralizando las reclamaciones y sugerencias que los trabajadores pudieran realizar al respecto, así como realizar la ponderación final del impacto real de las medidas adoptadas y la valoración de su grado de efectividad para lograr los objetivos marcados. También puede ser muy útil para evaluar y reformular el contenido del plan una vez cumplida su vigencia inicial, realizando un borrador de nuevas medidas de actuación sobre el que centrar el proceso de negociación. Como se puede apreciar, estas etapas coinciden con las fases que en la práctica ha de cumplir todo plan de igualdad (elaboración, aplicación, supervisión y reestructuración), deduciéndose entonces que la comisión de igualdad acompaña al plan de igualdad a lo largo de toda su existencia. De esta forma, las funciones atribuidas a la comisión de igualdad no serán puntuales, sino constantes a lo largo del tiempo.

Junto a estas funciones básicas, pueden encontrarse otras que completarían su ámbito funcional: prevenir, detectar y erradicar cualquier manifestación de discriminación de género, directa o indirecta; realizar la interpretación de preceptos confusos del plan de igualdad o de situaciones polémicas que, en materia de igualdad de oportunidades, se hayan podido suscitar en la empresa y que inicialmente no estuvieran recogidas en el plan de igualdad; e incluso, la posibilidad de elaborar dictámenes técnicos sobre aspectos relacionados con la igualdad de trato y oportunidades entre mujeres y hombres en el trabajo a solicitud de la dirección de la empresa, de los representantes de los trabajadores o de la comisión paritaria. Además, con el fin de garantizar que el principio de la igualdad de trato entre hombres y mujeres se respeta escrupulosamente en el acceso y en la promoción profesional en la empresa, se debería prever la participación en las comisiones de selección o en las comisiones de contratación de personal de uno o varios miembros de la comisión de igualdad, evitando así que tengan lugar ciertos episodios de discriminación en el empleo.

Al mismo tiempo, si se ha creado este tipo de comisión, será ella la que realice la investigación y el análisis de los hechos acaecidos en los supuestos de acoso laboral, y la que lleve a cabo la labor de mediación que pueda ser necesaria para solventar determinado tipo de controversias suscitadas entre la empresa y los trabajadores, los trabajadores entre sí, o incluso, entre personal de la empresa y personal ajeno a ella (como clientes o

\footnotetext{
${ }^{4}$ Sobre la utilidad de este tipo de comisiones para llevar a cabo la negociación, control y seguimiento de la implantación de los panes de igualdad en la empresa, véase MENDOZA NAVAS, N., MENÉNDEZ CALVO, R., OTAEGUI JÁUREGUI, A., (2008), "Comisiones específicas de igualdad, atribución puntual de competencias a la "Civea" o creación de otro tipo de comisiones, en AAVV, "La negociación colectiva en España: un enfoque interdisciplinar" (coord. por ESCUDERO RODRÍGUEZ, R.), Cinca, Madrid, págs. 314-325.

${ }^{5}$ Sobre las distintas fases que ha de integrar todo plan de igualdad, véase FABREGAT MONFORT, G., "Planes de igualdad", en AAVVV (2013) "Observatorio de la negociación colectiva: empleo público, igualdad, nuevas tecnologías y globalización”, (coord. por ESCUDERO RODRÍGUEZ, R., Ed. Cinca, págs. 176-187.
} 
proveedores) que actuará como trámite imprescindible antes de emprender acciones judiciales encaminadas a determinar si ha existido vulneración del derecho a la igualdad de trato y de oportunidades entre mujeres y hombres.

Y no sólo eso. Dado que el conocimiento generalizado del plan de igualdad, garantiza que los trabajadores soliciten las medidas que en él se recojan y exijan su cumplimiento, resulta aconsejable atribuir también a este órgano la labor de difusión no sólo de las actuaciones que se han puesto en marcha y los avances de la empresa en materia de igualdad de oportunidades, sino también, de las diferentes medidas normativas vigentes en materia de conciliación y promoción de la igualdad, paradójicamente, muchas veces desconocidas por los trabajadores, haciendo especial hincapié en las reformas normativas más recientes.

Razones de lógica, llevan a proponer que, la comisión de igualdad, además de paritaria, de composición equilibrada y configurada por un número no demasiado elevado (para no dificultar su labor) de personas que previamente hayan recibido formación en materia de género, debe garantizar cierta estabilidad en nombramiento a sus integrantes. Y es que sólo las personas que participaron en la elaboración del plan, conocen la situación de partida en la que se encontraba la empresa, la razón de ser y la finalidad que perseguían las estrategias de actuación que se han implantado, podrán realizar un seguimiento útil y efectivo del grado de cumplimiento del plan de igualdad y valorar, en sus justos términos, los alcances reales que se hayan podido alcanzar, emprendiendo acciones de mejora apropiadamente motivadas contando con una visión global del éxito o fracaso de las medidas inicialmente aprobadas. En caso contrario, la rotación excesiva de sus componentes, puede conllevar la aplicación de unas estrategias cambiantes, dispares y descoordinadas ${ }^{6}$.

En definitiva, una comisión de igualdad no es más que una concreta comisión de trabajo constituirá en el seno de una empresa que tiene atribuidas las funciones específicas de velar por el respeto de la igualdad de oportunidades en el entorno empresarial ${ }^{7}$.

\section{El papel de los planes de igualdad ante las solicitudes de adaptación de jornada previstas en el art. 34.8 ET tras la reformulación del derecho ofrecida por el RD-Ley $6 / 2019$}

Precisamente a estos efectos, conviene revalorizar el papel que puede desarrollar la comisión de igualdad en torno a la concreción de las solicitudes de adaptación de la duración y distribución de la jornada de trabajo, de ordenación del tiempo de trabajo y en la forma de prestación de servicios por motivos de conciliación, prevista en el art. 34.8 ET, y

\footnotetext{
${ }^{6} \mathrm{Y}$ es que se ha de tener presente que la existencia de una comisión de igualdad, puede facilitar en gran medida la elaboración y seguimiento que exige la puesta en práctica de todo plan de igualdad. Sobre la necesidad de realizar una correcta implantación y ejecución de los planes de igualdad en las empresas para poder obtener los distintivos de igualdad en las empresas, véase MENENDEZ CALVO, R. (2011), "Impacto laboral de la implementación de planes y políticas de igualdad en las empresas”, Anuario de la Facultad de Derecho, no. 4, págs. 167-197.

${ }^{7}$ Respecto a su estructura y funcionamiento, véase el estudio detallado que realiza MENDOZA NAVAS, N. (2010), “Comisiones de Igualdad”, en AAVV, “Observatorio de la negociación colectiva: empleo público, igualdad, nuevas tecnologías y globalización” (coord. por ESCUDERO RODRÍGUEZ, Ricardo), Cinca, Madrid, págs. 160-175.
} 
reformulada por el RD-Ley 6/2019. Literalmente, el legislador prevé que, es la empresa la que, en ausencia de reglas ad hoc plasmadas en negociación colectiva (puede ser a través de la vía del acuerdo colectivo y no necesariamente del convenio colectivo), abrirá un proceso de negociación con la persona trabajadora durante un periodo máximo de 30 días, finalizado el cual la empresa comunicará su decisión, aceptándola, formulando propuesta alternativa, o planteando una negativa justificada.

Pero, dentro de la empresa ¿quién desarrollará estas funciones? Habida cuenta del texto de la ley, se entiende que el empresario o la persona en la que éste delegue (que, posiblemente, será el director del departamento de recursos humanos, en las empresas que cuenten con esta figura). Y es entonces cuando se aprecia el importantísimo papel que los planes de igualdad pueden desarrollar al respecto, pues a través de estas herramientas, los negociadores pueden: no solo atribuir la decisión y justificación a una comisión paritaria, previamente formada en cuestiones de género (para lo cual, resulta particularmente útil crear una comisión de igualdad), sino también fijar una serie de reglas destinadas a concretar las condiciones y requerimientos que será necesario exigir para que la adaptación de horario o jornada solicitado por el trabajador no afecte a la organización productiva. Y no solo eso, aunque el art. 34.8 ET no haga referencia a este extremo, las reglas de la lógica permiten concluir la importancia de registrar el contenido y la respuesta ofrecida a cada solicitud, con el fin de garantizar que se otorga a todos los solicitantes una respuesta uniforme e igualmente razonada, sin realizar concesiones que dependan más de preferencias o simpatías personales, que de verdaderos criterios, objetivos y justificados, de concesión.

Para ello, se hace imprescindible interpretar el art. 34.8 ET a la luz de las previsiones de transparencia que formula el art. 47 LO 3/2007, y entender así, que los representantes de los trabajadores tienen derecho de información y acceso, a los registros de las actuaciones efectuadas ante las citadas solicitudes, tanto si la valoración y respuesta a la petición la formula directamente la empresa, o de si se canaliza a través de la comisión para la igualdad que se haya podido constituir al efecto. Y es que, no se puede negar que, aunque el legislador no lo advierta, dicha información constituye uno de los datos imprescindibles de los que pueden disponer los representantes legales de los trabajadores para efectuar el diagnóstico de la situación necesario para valorar la situación de la empresa.

Eso sí, cuando los representantes legales de los trabajadores manejen dicha información, no se puede olvidar que deberán mantener el deber de sigilo que marca el art. 65 ET. Y es que, aunque no existe ningún obstáculo para manejar y difundir datos tales como el número total de solicitudes aceptadas o rechazadas dentro del total de las presentadas, se ha de preservar en todo momento la intimidad de los solicitantes.

\section{Planes de igualdad de ámbito de sector. Su utilidad en el tejido productivo español}

Aunque el Estatuto de los Trabajadores plantee la negociación colectiva, como el instrumento idóneo para mejorar la igualdad de trato y oportunidades en el entorno empresarial (bien sea incluyendo la igualdad de género en sus negociaciones, bien elaborando 
un plan de igualdad cuando legal o voluntariamente resulte obligada a ello), se ha de ser consciente de que, en muchas ocasiones, no será fácil recurrir a esta vía de actuación. Y es que, dado que gran parte del tejido productivo de nuestro país se integra por PYMES, muchas veces, emprender un proceso de negociación colectiva de ámbito empresarial resultará muy complejo o incluso imposible (por lo que respecta a las empresas de menos de 6 trabajadores que carecen de representación sindical).

Adviértase que, aunque el reciente RD-Ley 6/2019 haya rebajado el número mínimo de trabajadores necesario para imponer la obligación de elaboración de un plan de igualdad de 250 a 50 (cambio que resultará plenamente operativo en el año 2021), realmente, esta modificación va a tener una importancia práctica mucho más reducida de lo que a primera vista parece. Como los datos oficiales se ocupan de confirmar, nada menos que el 99\% de las empresas españolas tienen actualmente menos de 50 trabajadores en su plantilla y, por lo tanto, ni siquiera tras la reforma, quedará afectada por la obligación de elaboración de un plan de igualdad ${ }^{8}$.

Ante esta situación, y aunque el legislador no haga referencia alguna a esta cuestión, se hace imprescindible revalorizar el papel que a estos efectos pueden desempeñar los acuerdos o pactos de empresa, por una parte, y por otra, los convenios colectivos de ámbito de sector. En este contexto, resulta fundamental reflexionar sobre el valor que, en su caso, podría tener un plan de igualdad de ámbito de sector ${ }^{9}$. La práctica demuestra que son diversos los sectores de actividad los que optan por asumir compromisos de este tipo, incluyéndolos como anexos a los convenios colectivos. Y si esto es así, ¿qué se pretende con ello?

Resulta obvio insistir en que, tal y como dispone la LO 3/2007, la obligación de elaborar planes de igualdad recae únicamente sobre las empresas ${ }^{10}$, bien porque superen el número mínimo de trabajadores exigido por la ley (50, 150 o 250, según el momento), porque previamente hayan sido sancionadas en materia de igualdad y no discriminación, o bien porque voluntariamente hayan asumido el citado compromiso en el seno de un proceso de negociación colectiva, por lo que, por supuesto, la hipotética existencia de un plan de igualdad de ámbito de sector nunca podrá eximir a las concretas empresas de cumplir las obligaciones legales que, en su caso, le correspondan. Tampoco las empresas incluidas dentro de su ámbito de aplicación a las que legalmente se les exija elaborar un plan de igualad pueden limitarse a copiar o remitir a lo previsto al plan de igualdad del ámbito de sector para cumplir su obligación. Y es que todo plan de igualdad exige un proceso previo de elaboración individualizada (cfr. art.46.1. in fine LO 3/2007), destinado a garantizar la razonabilidad de las medidas acordadas y su utilidad para solventar los problemas detectados.

Una vez hechas estas advertencias, son dos las cuestiones fundamentales que obliga a plantear la existencia de un plan de igualdad de ámbito de sector: $1^{\circ}$. Aunque la empresa

\footnotetext{
${ }^{8}$ Como consta en los últimos datos proporcionados por el Ministerio de Trabajo, Migraciones y Seguridad Social, en enero de 2019 http://www.ipyme.org/es-ES/ApWeb/EstadisticasPYME/Documents/CiifrasPYME-enero2019.pdf.

${ }^{9}$ Sobre este tema, véase, in extenso, FABREGAT MONFORT, G. (2012), "La negociación de los planes de igualdad en los convenios colectivos de ámbito sectorial", en AAVV, "Negociando la igualdad en las empresas: estado de la cuestión y estrategias para la implementación de una política de igualdad de género" (dir. MOLINA HERMOSILLA, O.), Comares, Granda, págs. 61-90.

${ }^{10}$ En este sentido, los arts. 45 y 46.1 de la LO 3/2007 no generan duda alguna acerca de ello.
} 
no alcance el número de trabajadores previsto normativamente para quedar obligada a elaborar un plan de igualdad, ¿puede un convenio sectorial obligar a todas las empresas incluidas en su ámbito de aplicación a elaborarlo, aunque no alcancen el número legalmente previsto de trabajadores? Y, ${ }^{\circ}$. ¿Puede un convenio sectorial introducir un plan de igualdad en virtud del cual se aprueben medidas de actuación que resulten directamente aplicables a todas las empresas incluidas dentro de su ámbito de aplicación?

Parece que, respetando siempre las reglas de la concurrencia de convenios, un análisis minucioso de la legislación vigente permite ofrecer una respuesta afirmativa a ambas cuestiones.

Así pues, es habitual que la negociación colectiva de ámbito de sector, utilice la fórmula del plan de igualdad para rebajar ligeramente la obligación legal de las empresas de su ámbito (obligando así a elaborar planes individualizados de igualdad, por ejemplo, a las empresas de más de 200, 150 o 100 trabajadores, según legislación anterior, o 40, 30, 25 , siguiendo la regulación vigente). Aunque menos frecuente en la práctica, no existe ningún obstáculo legal que impida a los planes sectoriales incluir compromisos directamente aplicables en todas las empresas de su ámbito y exigibles por todos los trabajadores. Un buen ejemplo de ello lo constituye el hecho de permitir disfrutar la hora por lactancia acumulada en jornadas completas, otorgar preferencia en la elección de turno de vacaciones a las personas con hijos menores de 12 años o declarar festivos no recuperables días señalados como el 24 o 31 de diciembre, entre otras situaciones.

Ahora bien, lo que no se puede negar es que, desaprovechando todo el potencial que podrían tener, la gran mayoría de planes de igualdad de ámbito de sector promulgados en España, más que en introducir compromisos concretos, se centran simplemente en adelantar a las empresas un esquema de las distintas materias que deberán abordar en el caso de que, en algún momento, alcancen el número de trabajadores suficiente para resultar obligadas a elaborar un plan de igualdad. Es decir, este plan de igualdad de ámbito de sector suele constar simplemente de indicaciones básicas que tienen como finalidad simplificar después la negociación en el ámbito de empresa ${ }^{11}$. Es entonces cuando resulta oportuno reparar en la que la modificación que introduce el RD-Ley 6/2019 sobre el art. 46 L0 3/2007, ha restado importancia a este tipo de indicaciones, haciéndolas prácticamente en superfluas, pues ya el propio texto de la ley enumera de forma minuciosa, las distintas materias que deberá abordar un plan de igualdad y que constituirán su contenido mínimo.

\section{La nulidad del plan}

Aunque la nulidad, total o parcial, del convenio colectivo es un asunto que ha sido abordado judicial y doctrinalmente en múltiples ocasiones ${ }^{12}$, no se ha prestado, por el momento

\footnotetext{
${ }^{11}$ Como se pone de manifiesto en AAVV (2016), "El principio de igualdad en la negociación colectiva”, SÁNCHEZ TRIGUEROS (dir), KAHALE CARRILLO y VELASCO PORTERO (coord.), Colección Informes y Estudios. Serie Relaciones Laborales, Ministerio de Trabajo y Asuntos Sociales, Madrid.

${ }^{12}$ Entre otros, véanse PÉREZ PÉREZ, M. (1982), “La nulidad parcial del convenio colectivo”, Revista española de De-
} 
la misma atención a la posible nulidad de un plan de igualdad. Pese a lo que a primera vista pudiera parecer, tampoco cabe aplicar por analogía las mismas reglas previstas para la nulidad del convenio, puesto que, no siempre la situación será coincidente. Recuérdese a estos efectos, que el legislador, a al ahora de contemplar cuáles son los trámites y presupuestos necesarios para elaborar un plan de igualdad, se muestra dividido entre la negociación y la consulta $^{13}$, lo que, sin duda, introduce un importante margen de confusión al respecto.

En torno a esta situación (interpretando conjuntamente tanto los apartados 2 y 4 del art. 45 LO 3/2007, como el art. 85 ET) se ha dicho que sólo las empresas que legal o administrativamente resulten obligadas a elaborar un plan de igualdad, deberán respetar un proceso de negociación con los representantes de los trabajadores, en el que, se infiere, que deberán respetarse las mismas mayorías necesarias para aprobar un convenio colectivo, sin las cuales, se deberá declarar la nulidad del plan. Por el contrario, en el resto de empresas que no alcance el suficiente número de trabajadores, pero que voluntariamente deseen implantar un plan de igualdad, bastará respetar un periodo de consultas con los representantes de los trabajadores (que, se deduce, terminará en la aprobación de un acuerdo de empresa sobre la materia) ${ }^{14}$.

Aunque, por el momento, siempre en torno a problemas prácticos suscitados en empresas de más de 250 trabajadores, nuestra jurisprudencia ha ido perfilando esta cuestión, insistiendo en la nulidad de un plan de igualdad impuesto unilateralmente por la empresa, y también, de aquél aprobado sin contar con la mayoría suficiente de representantes legales de los trabajadores, o excluyendo de la mesa de negociación a uno de los sindicatos de mayor representación en la empresa ${ }^{15}$. Pese a todo, quedan todavía diversas cuestiones pendientes de respuesta:

Resulta en la práctica bastante operativo que sea la comisión e igualdad (en el caso de que se haya constituido una en la empresa) la que prepare el borrador de plan de igualdad

recho del Trabajo, no. 9, págs. 613-640; GARCÍA BLASCO. J. (2009), "De la eficacia normativa del convenio colectivo y los efectos de su nulidad", Nul: estudios sobre invalidez e ineficacia, no.1.

${ }^{13}$ ROMERO FUENTES, J. (2018), "Algunas cuestiones en torno al deber de negociar planes de igualdad", comunicación presentada a la mesa "Los retos de la negociación colectiva en materia de desigualdad y brecha salarial", de las 2 es Jornades Juridiques de Dret Laboral i Sindical, "La precarietat laboral: desigualtat i discriminació", Barcelona, 8 y 9 de noviembre de 2018, página 2, soporte informático, http://www.ccoo.cat/ceres/documents/informes/comunicacio_Jessica_Romero_Fuentes_Premi_Josep_Devesa.pdf

${ }^{14}$ También al respecto, ROMERO FUENTES, J. (2018), "Algunas cuestiones en torno al deber de negociar planes de igualdad", comunicación presentada a la mesa "Los retos de la negociación colectiva en materia de desigualdad y brecha salarial", de las 2es Jornades Juridiques de Dret Laboral i Sindical, "La precarietat laboral: desigualtat i discriminació", Barcelona, 8 y 9 de noviembre de 2018, página 2, soporte informático, http://www.ccoo.cat/ceres/documents/informes/comunicacio_Jessica_Romero_Fuentes_Premi_Josep_Devesa.pdf

${ }^{15}$ GARCÍA CAMPÁ, S. (2014), en "Primera doctrina judicial sobre planes de igualdad en las empresas”, en AAVV, "Igualdad y democracia: el género como categoría de análisis jurídico: estudios en homenaje a la profesora Julia Sevilla", Ed. Cortes Valencianas, Valencia, se ocupa de realizar un recorrido por las distintas resoluciones judiciales dictadas en los últimos años ante los conflictos suscitados por la falta de acuerdo en lo que a la composición de la Comisión de igualdad se refiere. En concreto, en la pág. 284 analiza las SSTS de 5 de octubre de 2010 (RC 227/2009), 20 de octubre de 2011 (RC 23/2011) y 24 de enero de 2012 (RC 22/2011), en las que se sostiene que todos los sindicatos participantes en la mesa de negociación del convenio colectivo (aunque finalmente no hayan sido firmantes del mismo) tienen derecho a participar en la Comisión de igualdad (al igual que en cualquier otra comisión de trabajo constituida en la empresa, sea esta una comisión meramente negociadora o una comisión ejecutiva) en proporción a su representatividad, y si se les excluye sólo por el hecho de no haber sido firmantes del convenio colectivo, la designación de los miembros de la citada comisión deberá considerarse nula por haberse producido con violación del derecho fundamental a la negociación colectiva. 
que luego someter a negociación o consulta con el resto de representantes de los trabajadores. Pero ¿y si en la citada comisión de igualdad se ha excluido intencionadamente a algún sindicato? ¿La nulidad de la composición de la comisión de igualdad determina también la consiguiente nulidad del borrador del plan que ésta hubiera elaborado? ¿Quiere decir que tampoco sirve, ni siquiera el, estudio diagnóstico de la situación que, la citada comisión, hubiese preparado en virtud de los datos facilitados por la empresa? ¿Debe constituirse una nueva comisión de igualdad y reelaborar el trabajo? Se trata de cuestiones, más complejas de lo que a primera vista puede parecer, sobre las que poco a poco, deberá ir pronunciándose nuestra jurisprudencia. Conviene aclarar que, al igual que las empresas no tienen obligación de constituir comisión e igualdad, tampoco existe ninguna previsión legal qué clarifique cuáles deben ser sus competencias y cual su forma de constitución. Aunque pueda parecer obligado por las reglas de la lógica, no existe previsión alguna, que obligue a que las personas que integren, en su caso, la comisión de igualdad, deban seleccionarse entre los representantes de los trabajadores. Y es que, no existe ningún precepto en el que querer apoyar que este tipo de comisión deba ser un subgrupo de trabajo dentro del comité de empresa o de los delegados de personal. Parece entonces que será cualquier trabajador el que pueda desarrollar este tipo de funciones (en particular, si ha recibido formación adecuada para ello), siempre que su forma de designación haya quedado prevista en convenio colectivo, en propio plan de igualdad, se haya acordado en el seno de la comisión paritaria del convenio, o incluso, o sea fruto de acuerdo con el comité de empresa.

Otra de las posibles situaciones en las que cabría plantear la nulidad del plan de igualdad es la que proviene de la incorporación en su texto de una cláusula de vinculación a la totalidad, o incluso, de la inclusión de una cláusula de esta índole en el texto del convenio colectivo del que el plan de igualdad forma parte como anexo. Y es que, en virtud de ellas, una vez que judicialmente se hubiese declarado la nulidad de una de las previsiones del plan o convenio, en lugar de aplicar la respuesta legal que consiste en sustituir esta previsión por el equivalente legal, las partes acuerdan que la totalidad del texto firmado perderá su eficacia. Este tipo de compromisos se basan en considerar el texto del convenio (o en su caso, por qué no, del plan de igualdad), como un todo único, integrado por distintas cláusulas, de forma que la nulidad, por ilegal, de una de ellas, por voluntad expresa de las partes negociadoras, comunica su ineficacia al texto íntegro.

Pero no solo eso. Uno de los problemas que se va a plantear en un futuro inmediato con más frecuencia, proviene de la aplicabilidad real de una de las nuevas obligaciones exigidas a las empresas por el RD-Ley 6/2019. Y es que desde el momento en el que se crea un registro de planes de igualdad, y se obliga a las empresas a inscribir estos textos, ante la ausencia todavía del prometido desarrollo reglamentario, surge la duda de las consecuencias que se van a atribuir al hecho de no solicitar la inscripción del plan ¿se tratará de una conducta sancionable? ¿Provocará la ineficacia del texto? ¿También si la empresa no estaba obligada a elaborar un plan de igualdad, y lo ha hecho voluntariamente con la intención de mejorar la calidad en el empleo de sus trabajadores? Adviértase que respecto a los convenios colectivos solo se sanciona con la nulidad la no formalización por escrito (90.1 ET), mientras que, a la comunicación a la autoridad laboral para su depósito y regis- 
tro, solo se condicionan sus efectos erga omnes, convirtiéndolo en un acuerdo extraestatutario (86.3 ET), aunque no parece que las mismas consecuencias sean extrapolables a los planes de igualdad no registrados. Y es que, del tenor literal del segundo párrafo del art. 85.1 ET, interpretado a la luz de la razón de ser que inspira la LO 3/2007, se deduce que, por las propias características de la materia negociada, no caben acuerdos extraestatutarios, de eficacia limitada a los sujetos firmantes del acuerdo y sus representados, pues la finalidad que persiguen los planes de igualdad, quedaría totalmente frustrada.

Estas reflexiones, conducen inexorablemente a otra cuestión: ¿qué ocurrirá cuando, presentado un plan de igualdad a registro, la autoridad laboral detectara que una de sus cláusulas contraviene la legislación vigente? ¿Debe la autoridad laboral, en el momento de admitir el plan a registro, realizar un control de legalidad del mismo? ¿Con qué alcance y con qué consecuencias? Además, en el caso de existir una cláusula de vinculación a la totalidad y se detectaran, no ya cláusulas contrarias a la ley, sino cláusulas con un contenido meramente reiterativo de los derechos ya reconocidos en la legislación vigente (como viene siendo sorprendentemente habitual en los planes de igualdad aprobados hasta ahora por nuestras empresas ${ }^{16}$ ), ¿se puede negar la inscripción de estas previsiones? Y si es así ¿se podría considerar que se rompe por ello el equilibrio interno del texto que hubiese incluido un compromiso de vinculación a la totalidad?

\section{6. ¿Cabe el descuelgue del plan de igualdad?}

Como es sabido, el art. 82.3 ET, permite a las empresas, de forma motivada, apartarse intencionadamente de lo previsto en convenio colectivo. En concreto, podrán recurrir a esta medida cuando concurran causas ETOP que justifiquen esta decisión. Ahora bien, lo que tradicionalmente quedaba planteado como una solución extrema para garantizar la viabilidad de la empresa, con la reforma del año 2012, revitaliza su alcance, ampliándose de forma exponencial su aplicabilidad.

Sin duda inspirado en el clásico principio civil de rebus sic stantibus, del descuelgue salarial previsto en convenio sectorial que tradicionalmente permitía el ordenamiento laboral, se ha pasado a un abanico de objetivos potenciales del descuelgue lo que, unido a la primacía del convenio de empresa sobre el de ámbito de sector en una amplia lista de materias, intenta revitalizar la negociación colectiva de ámbito de empresa, Así, aunque nada impide tampoco a las empresas seguir descolgándose de lo previsto en un plan de igualdad de ámbito de sector, las numerosas materias en las que opera la primacía del convenio de empresa, en la práctica, convierte a los descuelgues, en la posibilidad de la empresa de inaplicar las condiciones previstas en su propio convenio cuando varíe su si-

\footnotetext{
${ }^{16}$ Forma patológica de elaboración de planes de igualdad, con la que, sin duda, se pone de manifiesto el profundo desconocimiento de negociadores, empresarios y trabajadores de cuáles son los derechos reconocidos en la legislación vigente, y por ese motivo, consideran un verdadero avance en el proceso negociación lo que no es más que una reiteración del texto de la norma, como se indica en AAVV (2016), "El principio de igualdad en la negociación colectiva", SÁNCHEZ TRIGUEROS (dir.), KAHALE CARRILLO y VELASCO PORTERO (coord.), Colección Informes y Estudios. Serie Relaciones Laborales, Ministerio de Trabajo y Asuntos Sociales, Madrid.
} 
tuación económica, técnica u organizativa. Ante esta situación, cabe plantear varias cuestiones, todavía no abordadas ni doctrinal ni jurisprudencialmente:

En el caso de que existiera un plan de igualdad de ámbito de sector, ¿podrían las empresas incluidas en él, descolgarse de sus previsiones? Y por otra, ¿puede una empresa descolgarse, con el paso del tiempo, de su propio plan de igualdad? ¿Y si éste se ha previsto, no por convenio colectivo de ámbito de empresa, sino por acuerdo de efectos colectivos? ¿Cabría recurrir a la técnica de la modificación sustancial de las condiciones de trabajo? Aunque no lo parezca, son cuestiones más complejas y de mayor trascendencia práctica de lo que a primera vista se pudiera anticipar.

Estrictamente, el art. 82.3 ET, al hacer referencia a la posibilidad de acordar el descuelgue con los representantes legales de los trabajadores, expresamente advierte que "el acuerdo de inaplicación, no podrá dar lugar al incumplimiento de las obligaciones establecidas en convenio relativas a la eliminación de las discriminaciones por razones de género o de las que estuvieran previstas en su caso, en el plan de igualdad aplicable en la empresa". Ahora bien, una valoración individualizada de esta afirmación, suscita dudas razonables en torno al verdadero alcance de esta disposición.

$1^{\circ}$ duda. Teniendo en cuenta que, la propuesta empresarial de inaplicación de las condiciones del convenio puede ser aceptada en periodo de consultas con los representantes de los trabajadores, remitirse para la solución de discrepancias a la comisión paritaria del convenio, recurrir a los procedimientos de solución extrajudicial de conflictos si se hubieran previsto, o en defecto de acuerdo y posibilidad de solución extrajudicial de conflictos, remitirse para la toma final de la decisión a la comisión consultiva nacional de convenios colectivos o a los órganos equivalentes previstos en las CCAA, ¿qué es lo que ha querido limitar el legislador? ¿Toda decisión que minore los derechos reconocidos en el plan de igualdad? ¿0 solo la que provenga de acuerdo con los representantes de los trabajadores como textualmente dispone el precepto? Si esto es así, ¿quiere decir que estas limitaciones, sí podrían venir impuestas, por ejemplo, por laudo arbitral? La comisión consultiva a la que se recurra en último lugar para la toma de la decisión final ¿puede sacrificar alguno de los derechos previstos en el plan persiguiendo el objetivo de adecuar la intensidad de las cargas empresariales, a sus posibilidades reales de asumirlas, cuando ha cambiado la situación de partida?

$2^{\circ}$ duda. Literalmente, el art. 82.3 ET hace referencia a la prohibición del descuelgue respecto a las obligaciones establecidas en convenio colectivo destinadas a "la eliminación de las discriminaciones por razones de género", o de las que "estuvieran previstas, en su caso, en el plan de igualdad". Con esta expresión, no del todo afortunada, ¿ se pretende limitar el descuelgue de cualquiera de las previsiones incluidas en el plan de igualdad, o solo las previstas para eliminar discriminación por razón de género que se hubiesen detectado?

Se trata de una cuestión de importancia fundamental para poder conocer cuál es el verdadero alcance de las posibilidades de inaplicación, total o parcial, del plan de igualdad por la vía del descuelgue. Basta solo un superficial acercamiento a los planes de igualdad para saber que, con ellos, no solo se pretenden eliminar factores de discriminación, sino favorecer la igualdad entre mujeres y hombres en todos los aspectos y facetas relacionados con la prestación de servicios, y para lograrlo, se ha de llevar una política mucho 
más amplia y variada que la que implicaría simplemente la eliminación de los factores de discriminación. Y es que, ¿existe discriminación, aunque sea indirecta, en establecer en la empresa un sistema de trabajo basado en la jornada partida? Los complementos por productividad en sí mismos ¿son discriminatorios? ¿Y el hecho de prever turnos rotatorios en el disfrute de las vacaciones? ¿Está discriminando a la mujer una empresa que no potencia que los varones disfruten de excedencias y reducciones de jornada por cuidado de hijo? ¿Se puede obligar a una mujer a asumir un puesto de dirección que no desea, solo para mantener el equilibrio de géneros? Contemplar o no contemplar, días por asuntos propios o la posibilidad de recurrir al teletrabajo, ¿puede considerarse una medida destinada a combatir episodios de discriminación, aunque sea indirecta, por razones de género? Parece entonces más razonable entender que los planes de igualdad, además de estar destinados a poner de manifiesto formas veladas de discriminación que subyacen en la estructura empresarial, evitando que se perpetúen, con el consiguiente perjuicio que ello causaría al empleo femenino, también dedican importantes esfuerzos a favorecer que hombres y mujeres tengan la misma presencia en todas las categorías y modalidades contractuales, y a estudiar estrategias destinadas a atenuar la brecha de género, lo que comprende actuaciones muchísimo más variadas que lo que meramente implicaría reconocer episodios de discriminación. Y si esto es así ¿qué es lo que el art. 82.3 ET intenta evitar? ¿Inaplicar cualquiera de las medidas previstas en el plan de igualdad, o solo las expresamente destinadas a impedir que se desarrollen prácticas discriminatorias ( $\mathrm{y}$, por lo tanto, recodemos que, ilegales por propia naturaleza, sin necesidad de que el plan las recoja como tales) en el concreto entorno empresarial al que queda referido?

3ํ duda. Cuando el art. 82.3 ET hace referencia a la imposibilidad del descuelgue de las medidas antidiscriminatorias previstas en convenio colectivo o en el plan de igualdad aplicable en la empresa ¿se refiere a cualquier plan que resulte aplicable a esa concreta empresa, como podrían ser las previsiones de género incluidas en el plan de sector correspondiente o solo a lo previsto en el seno de la propia empresa?

Para contestar a esta pregunta, resulta fundamental recordar que, entre las materias en las que el convenio de empresa tiene prioridad aplicativa sobre la regulación sectorial (84.2 ET) se encuentran, formando parte de una lista tasada, tanto c) "El horario y la distribución del tiempo de trabajo, el régimen de trabajo a turnos y la planificación anual de las vacaciones", como "la adaptación en el ámbito de empresa del sistema de clasificación profesional de los trabajadores", o f) "Las medidas para favorecer la conciliación entre la vida laboral, familiar y personal", aspectos en los que, por lo general, suele centrarse todo plan de igualdad, por lo que deja poco margen a un hipotético descuelgue de previsiones destinadas a favorecer la igualdad de género que se hubieran podido incluir en un plan de igualdad sobre el que después poder descolgarse por razones ETOP, (salvo, quizá todo lo relacionado con la preferencia en el empleo y acceso al ascenso del sexo menos representado, respecto al cual resulta difícilmente justificable su eliminación por causas ETOP).

A la vista de estas reflexiones, puede todavía afirmarse que, aunque el legislador permite el descuelgue de aspectos tales como la jornada de trabajo, el horario y distribución del tiempo de trabajo, el régimen de trabajo a turnos, el sistema de remuneración y 
cuantía del salario, el sistema de trabajo y rendimiento y las mejoras voluntarias de la Seguridad Social (82.3 ET), con las cuales se pueden conseguir grandes avances en la igualdad de género en la empresa, si éstas medidas se han incluido en el texto de un plan de igualdad, ¿serán inamovibles? 0, por el contrario, ¿se pueden inaplicar por causas ETOP las iniciativas destinadas a favorecer la calidad de vida de los empleados en otros aspectos, pero no las que directa o indirectamente aborden aspectos vinculados a la igualdad de presencia de mujeres y hombres en el entorno empresarial?

Habría que plantearse que, si verdaderamente se desea hacer una interpretación tan restrictiva de las posibilidades de descuelgue del plan de igualdad establecido a la empresa, en realidad se está haciendo un flaco favor al objetivo de lograr una presencia equilibrada de mujeres y hombres en todas las categorías y niveles retributivos, pues obviamente, las empresas conocedoras de tal situación, van a ser poco propicias a incluir en sus planes de igualdad medidas ambiciosas y generosas, si sospechan del riesgo absoluto de la inamovilidad que afectaría, según algunas posturas doctrinales, a toda cuestión vinculada a aspectos de género, lo que sin duda contribuye a acentuar la práctica ya generalizada de convertir los planes de igualdad en un conjunto programático de deseos generales, sin materializarlos en compromisos concretos de actuación. Y es que optar por otra solución implicaría, de prosperar esta teoría interpretativa, asumir un coste permanente e inflexible, sean cuales sean, las circunstancias que pueda atravesar la empresa a lo largo del tiempo, del que solo se podrá liberar la empresa a través de un nuevo convenio colectivo. Si esto es así, ¿no resulta paradójico que el legislador no haya querido otorgar esta protección reforzada ni siquiera a la cuantía retributiva de los empleados (objeto más frecuente de los descuelgues efectuados en nuestro país), a pesar del valor fundamental que el salario desempeña en el contrato de trabajo, como contrato cambiario? Así las cosas, no parece que, el art. 82.3 ET esté impidiendo el descuelgue parcial y razonado de alguna de las medidas que se hubieran podido incluir en el plan, siempre que, sin que ello pueda llevar en modo alguno a legitimar prácticas discriminatorias, se justifique su relación directa con las causas ETOP que sustentan esta decisión.

Tampoco se puede olvidar que, en el tejido productivo español, muchos de los planes de igualdad existentes no están incluidos en un convenio colectivo, sino que se aprobaban por la vía del acuerdo de empresa de efectos colectivos (normalmente por tratarse de empresas que no superaban el número mínimo de trabajadores establecido en la norma para convertir en obligatoria la elaboración de un plan de igualdad), ámbito en el que no cabe el descuelgue sino que deberá operar una modificación sustancial de las condiciones de trabajo (no sometida a las mismas limitaciones ${ }^{17}$ ), o simplemente, se intentará alcanzar un nuevo acuerdo novatorio en el que se intuyen muchos menos problemas prácticos para sacrificar previsiones destinadas a favorecer la conciliación, a cambio de garantizar el mantenimiento del empleo o del nivel retributivo de los empleados.

\footnotetext{
${ }^{17}$ Adviértase que, el art. 41 ET, al regular la figura de la modificación sustancial de las condiciones de trabajo, no hace referencia alguna a los planes de igualdad, ni introduce previsión o limitación de ningún tipo en la que poder otorgar un valor reforzado a las cláusulas que tuvieran perspectiva de género. Éstas y otras cuestiones las analiza ALVAREZ CUESTA, H. (2016), "Igualdad por razón de género en supuestos de descuelgue convencional o modificación sustancial de condiciones", en AAVV, "Propuestas para la igualdad por razón de género en los procesos de negociación colectiva” (coord. por ALVAREZ CUESTA, RODRÍGUEZ ESCANCIANO, MARTINEZ BARROSO), Aranzadi, Navarra, págs. 79-101.
} 


\section{Propuestas de mejora}

Sin duda, la reforma introducida por el RD-Ley 6/2019 pretendía mejorar sustancialmente la regulación de los planes de igualdad, eliminando parte de los problemas y deficiencias a los que se enfrentaban, con el fin de conseguir mejorar la igualdad de género en las empresas. Pese a todo, no se puede desconocer el hecho de que todavía existen serios obstáculos que dificultan que la plena igualdad en el ámbito empresarial, obstáculos que difícilmente se pueden remover a través del esperado desarrollo reglamentario, todavía pendiente. Dicho reglamento abordará aspectos tales como el registro de planes de igualdad, el procedimiento de seguimiento y evaluación o las auditorias salariales, pero no otras que exceden el contenido de la ley y, por lo tanto, no son susceptibles de subsanar recurriendo a la vía del desarrollo reglamentario. Y es que por mucho que empresas y trabajadores quieran facilitar la conciliación de la vida laboral y familiar en su concreto entorno profesional, como pieza clave para alcanzar la igualdad de género en todas las categorías y modalidades contractuales, hay aspectos que convendría facilitar con carácter general.

Aunque cada CCAA asume competencias en educación en su respectivo ámbito, sorprende comprobar, el carácter tan limitado que hoy en día tiene, con carácter general, la escolarización pública. Y es que, como es sabido, a ella sólo pueden acceder mayores de tres años, únicamente está activa 9 meses al año (en lugar de los 11 que comprende cualquier actividad productiva), y únicamente abarca la franja horaria comprendida entre las $9.00 \mathrm{~h}$ y las 17.00 h, periodo de tiempo muy diferente, como se puede comprobar, a la duración y distribución media de las jornadas laborales en España, obligando a los trabajadores a buscar otras formas de conciliación en los periodos restantes, muchas veces en detrimento de sus oportunidades laborales. Y es que, por muy implicados que puedan estar los negociadores, existen problemas de base que la negociación colectiva no puede solventar, y que corresponde atender a las Administraciones públicas, favoreciendo la existencia de servicios públicos de calidad a los que puedan recurrir las personas trabajadoras sin coste añadido.

En este orden de cosas, aunque muchas veces pase desapercibido, existe un serio obstáculo a este tipo de previsiones: el sistema de bonificaciones a la sustitución de personas en situación de reserva de plaza por motivos familiares, previsto en nuestro ordenamiento jurídico. Adviértase que, en contra de lo que a primera vista puede parecer, la sustitución de un trabajador en situación de baja maternal o paternal (hoy ya denominada suspensión "por nacimiento de hijo", sin realizar distinciones entre géneros) o excedencia por cuidado de hijos, no genera coste alguno para la empresa, pues el contrato de interinidad celebrado con el sustituto lleva aparejadas importantísimas bonificaciones en la cuota de cotización (del 100\% en caso de maternidad o paternidad, y del 95\% durante el primer año de excedencia por cuidado de hijo o familiares) ${ }^{18}$. Ahora bien ¿qué ocurre cuando han transcurrido las 16 semanas de duración de este permiso y la persona trabajadora no se ha reincorporado todavía por estar disfrutando de la lactancia acumulada o de la pospo-

${ }^{18}$ Respectivamente RD-Ley 11/1998, Ley 12/2001 y RD-Legislativo 2/2015. 
sición de las vacaciones? ${ }^{19}$ Pues lo que ocurre es que finalizaría el contrato de interinidad inicialmente firmado y, si la empresa desea prolongar esta sustitución hasta el momento en el que se produzca la reincorporación efectiva del trabajador sustituido, deberá ahora celebrar un contrato eventual (incluso con la misma persona que estuviera realizando ya la sustitución) para cubrir las necesidades productivas que surjan en la empresa durante el periodo de vacaciones y de lactancia acumulada, modalidad contractual sobre la que, paradójicamente, por el momento, no existe ningún tipo de bonificación en la cotización. Y es que, conviene recordar que, aunque el legislador aclara que el contrato de interinidad podrá celebrarse para sustituir el porcentaje de jornada que deja vacante un trabajador en situación de reducción de jornada por cuidado de hijos o familiares (art. 5 RD 2027/1998), no existe extensión similar para otros periodos. Así, por ejemplo, durante la acumulación de las horas de lactancia y durante el disfrute de las vacaciones, dado que el trabajador no se encuentra en situación de suspensión del contrato, sino en activo, disfrutando de uno de los permisos retribuidos que, por motivo de descanso o conciliación, reconoce nuestra normativa, la empresa no puede recurrir al contrato de interinidad, sino al eventual (ya sin bonificación, con las incomodidades que ello puede generar en el proceso productivo) ${ }^{20}$.

Por este motivo no se puede dejar de reclamar a los poderes públicos la modificación del régimen jurídico actualmente vigente, con el fin de poder poner en práctica la razonable medida de prolongar el contrato de interinidad, y con él, las intensas bonificaciones que éste contempla, hasta el momento en el que se produzca la reincorporación efectiva al trabajo de la persona sustituida, independientemente de si ésta se ha acogido únicamente al periodo de suspensión del contrato previsto por la ley, o si disfruta de cualquier otra fórmula de conciliación que pueda requerir su sustitución efectiva en el entorno laboral. Hasta que eso no ocurra, se estará lastrando cualquier intento empresarial de mejorar los derechos de conciliación previstos en la legislación laboral, a pesar de la importantísima mejora en la calidad de vida de las personas con cargas familiares que ello implicaría. En concreto, se

\footnotetext{
${ }^{19}$ Debe recordarse que, si optase por solicitar una excedencia por cuidado de hijos o incluso, si disfruta de un periodo adicional de suspensión con reserva de plaza previamente negociado con su empresa (en virtud de la cual se amplíe la duración de la excedencia por cuidado de hijo o familiares), también podría prolongar el contrato de interinidad, pues técnicamente el sujeto se encuentra todavía en situación de suspensión del contrato con reserva de plaza, aunque las bonificaciones previstas únicamente se podrían mantener durante el tiempo de suspensión previsto en el Estatuto de los Trabajadores (16 semanas en caso de cuidado de hijo, y hasta tres años en caso de excedencia por cuidado de familiares, con un importe decreciente durante el $1 \stackrel{0}{ }, 2^{\circ}$ o 3 o año), sin que por el momento el legislador haya reparado también en la necesidad de bonificar los periodos de duración del contrato que deriven de una previa ampliación contractual o convencional de los motivos de suspensión del contrato con reserva de plaza por contingencias familiares. Pese a todo, debe advertirse que, aunque útiles en ciertos casos, al ser estos periodos adicionales de suspensión del contrato con reserva de plaza ni retribuidos ni protegidos con ningún tipo de prestación a cargo de la Seguridad Social, no se trata de previsiones demasiado frecuentes en nuestra negociación colectiva, por no haber demasiada demanda de solicitantes.

${ }^{20}$ Consciente de estos problemas, la STS (Sala de lo Social), de 30 de octubre de 2019 (no. . rec. 1070/2017), además de recordar que, con carácter general, se niega la utilización del contrato de interinidad para suplir a trabajadores en vacaciones, hace referencia a la regla de la previsibilidad o imprevisibilidad de la necesidad empresarial, como elemento diferenciador entre la causa que diferencia el contrato de interinidad del contrato eventual. Así pues, aunque no sea éste el tema enjuiciado en esta ocasión, es precisamente en esta reflexión, en la que se podría sustentar la posibilidad de prorrogar el contrato de interinidad en los casos en los que la necesidad empresarial provenga de la acumulación de las horas por lactancia o del disfrute de las vacaciones fuera del turno inicialmente previsto por razón de nacimiento de hijo (o, por qué no, de una situación de Incapacidad Temporal concurrente en el tiempo con el periodo inicialmente asignado de disfrute de vacaciones). Y es que, en esos casos, no puede negarse que no concurre la previsibilidad que sí existe en los restantes periodos de disfrute de vacaciones.
} 
ha de ser consciente que, en muchos casos, el abandono, temporal o permanente, del puesto de trabajo por parte de las trabajadoras con hijos, se produce a raíz del nacimiento de éstos, situación que deja una importante huella en la carrera de cotización del sujeto, efectos perjudiciales que, sin duda, la acumulación de la lactancia y las vacaciones podrían atenuar.

Precisamente sobre el tema de la reducción de jornada por cuidado de hijos o familiares, uno de los aspectos que sería conveniente mejorar es la redacción literal del art. 37 ET. Y es que el legislador, después de proclamar que constituyen un derecho individual de los trabajadores de la empresa, sean éstos hombres o mujeres (37.6 ET), detalla en el apartado siguiente (37.7 ET) que la concreción horaria y la determinación de las reducciones de jornada "corresponderá a la persona trabajadora dentro de su jornada ordinaria", previendo, a título de excepción que "no obstante, los convenios colectivos podrán establecer criterios para la concreción horaria de la reducción de jornada (...atendiendo a) las necesidades productivas y organizativas de las empresas".

Si esto es así, ¿cómo pueden proceder las PYMES, con escasos trabajadores, en las que la concurrencia de varias solicitudes de reducción de jornada entre los miembros de su plantilla, puede dejar totalmente desestructurada la estrategia de organización empresarial seguida hasta ese momento? Se trata de una situación que, en particular, deja sentir sus efectos con más fuerza en empresas de menos de 6 trabajadores en las que, además, se realicen actividades especializadas. Y es que, habitualmente, en estos casos, debido a la formación requerida, resulta complejo encontrar personas dispuestas a desempeñar de forma temporal y a tiempo parcial un contrato de interinidad por el tiempo previsto de duración de la reducción de jornada solicitada por sus compañeros (piénsese por ejemplo, en clínicas oftalmológicas, veterinarias, ópticas, etc.), y en las que normalmente no existe un convenio de empresa en el que prever tales cuestiones, por lo que la que única previsión posible debería haberse incluido en un convenio de sector, normalmente, como se ha expuesto, poco implicados en las cuestiones de género. No se trata ésta de una cuestión baladí, ni mucho menos, y es que lejos de considerar que las restricciones que haya impuesto el convenio colectivo lo que persiguen es limitar la libertad de las personas trabajadoras a adaptar la duración de su jornada de trabajo en atención a las necesidades individuales de conciliación de cada persona ¿no genera el efecto contrario, mucho más pernicioso, de lastrar la contratación femenina en los puestos más cualificados, y por ello de difícil cobertura temporal ${ }^{21}$ ? Es sin duda una cuestión dura, difícil de abordar, pero de

\footnotetext{
${ }^{21}$ Sobre esta cuestión, jurisprudencialmente, se empieza a sugerir deslindar el derecho a la reducción de jornada por cuidado de hijo (37.6 ET), que se considera un derecho individual e indisponible de la persona trabajadora, de su concreción horaria (37.7 ET), en la que esta libertad individual puede quedar sujeta a ciertas restricciones. Así, aunque se admite sin reservas que el trabajador es plenamente libre para determinar, dentro de la horquilla permitida por el legislador, en qué porcentaje desea reducir su jornada diaria de trabajo, la determinación de las horas exactas en las que materializará este derecho, ya no depende siempre de su exclusiva voluntad. Y es que, aunque en principio, se entiende que la concreción horaria de este derecho, también corresponde al propio trabajador que ha solicitado la medida, se admite que, en situaciones concretas, atendiendo a las circunstancias que rodean la prestación de servicios y las características de la organización empresarial, "puede decaer este derecho, como ocurriría en supuestos de abuso de derecho, transgresión de la buena fe, o manifiesto quebranto para la empresa". En otras palabras, aunque en principio, cada persona trabajadora pueda materializar tal reducción de jornada en la franja horaria que mejor le convenga, se permite al empresario, "demostrar que confluyen razones más poderosas, normalmente organizativas, que impiden su disfrute en los términos previstos por el trabajador", aunque el convenio colectivo no haya incluido previsión alguna al respecto o no
} 
imprescindible reflexión habida cuenta de la persistente brecha de género, por el momento imposible de combatir.

\section{Bibliografía}

AAVV, "Memoria sobre la situación socioeconómica y laboral de España”, Consejo Económico y Social, Madrid, 2019.

AAVV (2016), "El principio de igualdad en la negociación colectiva", SÁNCHEZ TRIGUEROS (dir.), KAHALE CARRILLO y VELASCO PORTERO (coord.), Colección Informes y Estudios. Serie Relaciones Laborales, Ministerio de Trabajo y Asuntos Sociales, Madrid. ALVAREZ CUESTA, H. (2016), “Igualdad por razón de género en supuestos de descuelgue convencional o modificación sustancial de condiciones", en AAVV, "Propuestas para la igualdad por razón de género en los procesos de negociación colectiva” (coord. por ALVAREZ CUESTA, RODRÍGUEZ ESCANCIANO, MARTINEZ BARROSO), Aranzadi, Navarra, págs. 79-101.

FABREGAT MONFORT, G. (2012), "La negociación de los planes de igualdad en los convenios colectivos de ámbito sectorial”, en AAVV, "Negociando la igualdad en las empresas: estado de la cuestión y estrategias para la implementación de una política de igualdad de género" (dir. MOLINA HERMOSILLA, 0.), Comares, Granda, págs. 61-90.

FABREGAT MONFORT, G. (2013), "Planes de igualdad”, en AAVVV “Observatorio de la negociación colectiva: empleo público, igualdad, nuevas tecnologías y globalización", (coord. por ESCUDERO RODRÍGUEZ, R., Ed. Cinca, págs. 176-187.

GARCÍA BLASCO. J. (2009), "De la eficacia normativa del convenio colectivo y los efectos de su nulidad", Nul: estudios sobre invalidez e ineficacia, nํ‥1, soporte informático.

GARCÍA CAMPÁ, S. (2014), "Primera doctrina judicial sobre planes de igualdad en las empresas”, en AAVV, “Igualdad y democracia: el género como categoría de análisis jurídico: estudios en homenaje a la profesora Julia Sevilla", Ed. Cortes Valencianas, Valencia, págs. 281-292.

MENDOZA NAVAS, N. (2010), “Comisiones de Igualdad”, en AAVV, “Observatorio de la negociación colectiva: empleo público, igualdad, nuevas tecnologías y globalización" (coord. por ESCUDERO RODRÍGUEZ, R.), Cinca, Madrid, págs. 160-175.

MENDOZA NAVAS, N., MENÉNDEZ CALVO, R., OTAEGUI JÁUREGUI, A. (2008), “Comisiones específicas de igualdad, atribución puntual de competencias a la "Civea" o creación de otro tipo de comisiones, en AAVV, "La negociación colectiva en España: un enfoque interdisciplinar” (coord. por ESCUDERO RODRÍGUEZ, R.), Cinca, Madrid, págs. 314-325.

\footnotetext{
exista convenio o acuerdo colectivo aplicable. Sobre esta cuestión, véase la muy ilustrativa STSJ de Andalucía (Sevilla), Sala de lo Social, de 1 de febrero de 2018 (no. sentencia 343/2018). A estos efectos, resulta interesante destacar que, aunque el art. 34.8 ET (recientemente modificado por el RD-Ley 6/2019) tiene unos presupuestos y un campo de aplicación distinto al contemplado en el art. 37.7 ET, en realidad, mantiene con éste muchos puntos de conexión. Y es que, en ambos casos, previa justificación, y con carácter excepcional, se permite anteponer las necesidades empresariales a las necesidades personales de los trabajadores.
} 
MENENDEZ CALVO, R. (2011), "Impacto laboral de la implementación de planes y políticas de igualdad en las empresas”, Anuario de la Facultad de Derecho, nº. 4, págs. 167-197. PÉREZ PÉREZ, M. (1982), "La nulidad parcial del convenio colectivo”, Revista española de Derecho del Trabajo, nº. 9, págs. 613-640.

ROMERO FUENTES, J. (2018), "Algunas cuestiones en torno al deber de negociar planes de igualdad", comunicación presentada a la mesa "Los retos de la negociación colectiva en materia de desigualdad y brecha salarial", de las 2es Jornades Juridiques de Dret Laboral i Sindical, "La precarietat laboral: desigualtat i discriminació", Barcelona, 8 y 9 de noviembre de 2018, soporte informático, http://www.ccoo.cat/ceres/documents/informes/comunicacio_Jessica_Romero_Fuentes_Premi_Josep_Devesa.pdf 